\title{
Drying Climates and Gendered Suffering: Links Between Drought, Food Insecurity, and Women's HIV in Less-Developed Countries
}

\author{
Kelly F. Austin ${ }^{1}$ (D) Mark D. Noble ${ }^{2}$. Virginia Kuulei Berndt ${ }^{3}$
}

Accepted: 13 November 2020 / Published online: 24 November 2020

(c) Springer Nature B.V. 2020

\begin{abstract}
HIV/AIDS represents the leading cause of death among women of reproductive age globally, and gender inequalities in the burden of HIV/AIDS are most pronounced in poorer countries. Drawing on ideas from feminist political ecology, we explore linkages between suffering from drought, food insecurity, and women's vulnerability to HIV. Using data from 91 less-developed countries, we construct a structural equation model to analyze the direct and indirect influence of these factors, alongside other socio-economic indicators, on the percentage of the adult population living with HIV that are women. We find that droughts are significant in shaping gender inequalities in the HIV burden indirectly through increased food insecurity. We draw on prior research to argue that due to gendered inequalities, food insecurity increases women's vulnerability to HIV by intensifying biological susceptibilities to the disease, reducing access to social and health resources, and motivating women to engage in risky sexual behaviors, such as transactional sex. Overall, our findings demonstrate that droughts serve as an important underlying factor in promoting HIV transmission among vulnerable women in poor countries, and that food insecurity is a key mechanism in driving this relationship.
\end{abstract}

Keywords HIV/AIDS · Drought · Environment $\cdot$ Gender $\cdot$ Food insecurity

Kelly F. Austin

kellyaustin@lehigh.edu

1 Department of Sociology and Anthropology, Lehigh University, 31 Williams Drive, Bethlehem, PA 18015, USA

2 Department of Sociology and Anthropology, Susquehanna University, 322 Fisher Hall, 514 University Avenue, Selinsgrove, PA 17870, USA

3 Department of Sociology and Criminal Justice, University of Delaware, 322 Smith Hall, 18 Amstel Avenue, Newark, DE 19716, USA 


\section{Introduction}

The COVID-19 pandemic has brought renewed interest in infectious diseases, including illuminating the connection between environmental degradation and infectious disease spillover (e.g. Carrington 2020). The United Nations reports (UNEP 2016) that environmental changes like climate change and deforestation contribute to the emergence of novel diseases; but these factors might also shape vulnerabilities to established diseases, such as HIV. Indeed, while the majority of zoonotic diseases emerge from human and animal contact driven by encroachment into natural environments, ongoing vulnerability to infectious diseases are also shaped by social inequalities that mediate people's ability to cope with environmental change.

HIV is one such disease that exploits existing social and economic inequalities and vulnerabilities, as current trends indicate that women in less-developed countries are especially likely to contract HIV (UNAIDS 2017). ${ }^{1}$ The feminization of HIV is especially striking in Sub-Saharan Africa where young women aged 15-24 are more than twice as likely as their male counterparts to become HIV positive (UNAIDS 2017). Identifying the diversity of factors that contribute to gender inequality in the global HIV burden is important and timely research, especially against the backdrop of a youth bulge in Sub-Saharan Africa, with larger and larger proportions of the population becoming sexually active (UN 2019).

Most current attempts to explain women's disproportionate share of global HIV cases focus on a mix of biological, social, cultural, and economic inequalities that women face relative to men (e.g. Heimer 2007; Stillwaggon 2002). Our study attempts to build on such work and bring the environment and climate-related disasters into a discussion of the feminization of HIV. In less-developed countries, where the overwhelming majority of global HIV cases are concentrated, most societies practice strict gender norms, where women typically represent the household and environmental managers (Agarwal 1997; Hovorka 2006; Rocheleau et al. 1996). As such, women carry the primary responsibility for growing and harvesting food, gathering firewood, fetching water, and other tasks that transform environmental resources into household needs. Thus, changes to the environment may compromise women's health in unique ways.

This paper specifically will focus on the effects of environmental change due to droughts, for a number of reasons. Droughts profoundly affect people's health, well-being and livelihoods. For example, droughts can impact access to safe drinking water, diminish food cultivation, and harm livestock (FAO 2011; Sam et al. 2019). Droughts are increasing in frequency and intensity over time, and have clear links to being caused by climate change (e.g. Lewis 2017; Marvel et al. 2019). In fact, droughts represent the most widespread climate-related disaster (CRED 2016; FAO 2020). In 2016, 94\% of those affected by climate-related disasters were affected by droughts (CRED 2016). Droughts are also distinct from other disasters, such as storms or floods, in that they are long-term events, often unfolding over weeks, months, or even years (CRED 2016; FAO 2011). Thus, their impacts to people are especially pronounced, particularly in less-developed countries that lack infrastructure and feature a more direct dependence on the natural environment for household resources like food (CRED 2016; FAO 2011; Lewis 2017; Memon et al. 2018).

\footnotetext{
1 Throughout this article, less-developed countries are defined as countries falling within the lower three quartiles of the World Bank income classification of countries, which is based on per capita GDP.
} 
Food insecurity represents one of the most widespread consequences of suffering from drought (e.g. FAO 2020), and also has important relevance for creating gender-based vulnerabilities to HIV (e.g. Masa et al. 2019). Prior research identifies several important physiological and social factors that link food insecurity to women's vulnerability to HIV in less-developed countries. For example, food insecurity increases susceptibility to potential exposure and infection from HIV through macro and micro nutrient deficiencies (e.g. Friis 2005; Gillespie and Kadiyala 2005), and women are more likely to be food insecure than men (WFP 2020). Women in communities facing food insecurity also are less likely to attend school or access health services, including reproductive services that could protect them against HIV (Belachew et al. 2011; Hadley et al. 2012). Furthermore, hunger and food insecurity are key factors motivating women's engagement in early marriage, commercial sex, transactional sex relationships, and other forms risky sex (e.g. Masa et al. 2019; Miller et al. 2011; Pellowski et al. 2018; Tsai and Weiser 2014).

This study seeks to illuminate the underlying role of environmental change and disasters in conditioning vulnerabilities to HIV. While many infectious diseases like HIV/AIDS do not have a direct link to the environment in their transmission patterns or vectors, disasters such as drought can still have a significant influence on the social conditions that shape and enhance vulnerabilities. As women largely represent the managers of environmental and household resources in developing countries, factors that degrade the environment or lead to the inability of women to secure access to food, drinking water, or other basic elements, are likely to disproportionately impact women's health in a number of complex ways.

Given our specific focus on women's vulnerability to HIV, we employ a relevant measure as our key outcome, the percentage of the adult population living with HIV who are women, to appropriately measure the unequal distribution of HIV cases by gender. In order to properly account for the dynamic or underlying relationships involving suffering from drought, food insecurity, and women's access to social and health services, we utilize structural equation modeling. Such an approach allows us to explicitly model direct and indirect effects, and to assess the importance of them. This modeling strategy can help to illuminate the role of underlying factors and interrelated circumstances that increase women's vulnerability to HIV/AIDS in developing countries.

\section{Women, HIV/AIDS, and the Environment}

Although men were initially more likely to have HIV/AIDS when the disease emerged in the 1980s and 90s, there has been a clear trend toward the feminization of HIV over time, as women now represent the global majority of HIV/AIDS cases (UNAIDS 2017). Although globally women are most likely to be HIV-positive, there is tremendous variation in the share of women living with HIV across countries. Women represent over $60 \%$ of HIV/AIDS cases in Sub-Saharan Africa, while in the Middle East and North Africa women comprise only about 35\% of total HIV/AIDS cases (World Bank 2019). Despite this variation, HIV/AIDS is now the leading cause of death for women aged 30 to 49 and the third leading cause of death among young women aged 15 to 19 worldwide (UNAIDS 2017).

For a variety of reasons, HIV infections represent a greater risk to women than to men. Some of these factors are biological in nature. For example, HIV transmission occurs through permutation of the cells of the vagina, which represent a relatively larger surface area in comparison to men's genitalia (UNAIDS 2017). In addition, there is increased 
exposure time of fluid in females, as well as higher concentration of HIV in semen as compared to vaginal secretions (UNAIDS 2017). Hormonal fluctuations and a higher prevalence of STIs among women, overall, have also been linked to an increased likelihood of contracting HIV (Campbell et al. 2008).

Biological factors alone, however, are insufficient in explaining gender inequality in the HIV burden; social, cultural, and economic inequalities that women face are often more salient, especially in less-developed countries where gender disparities are most pronounced (Austin and Noble 2014; Heimer 2007; Smith 2002). The concept of structural violence is useful when examining gender inequalities in health by drawing attention to how the arrangement of larger structural forces in society benefit some groups and limit the well-being or potential of others (e.g. Farmer 1999). Patriarchal structures and hierarchies uphold the idea that men are more valuable than women and should have more authority in society, and can put women's health at risk in a variety of ways, including violence against women, deprioritizing women's health, access to medical care, and education, and restricting participation in activities outside of the home (Campbell et al. 2008; Farmer 1999; Heimer 2007; Smith 2002).

Indeed, the importance of aspects like access to education, healthcare, or contraceptives are well-established in cross-national empirical research on women's HIV/AIDS (e.g. Austin and Noble 2014; Austin et al. 2017), however, much less attention has been devoted to considering the role of environmental factors. Insights from feminist perspectives on the environment, such as feminist political ecology and ecofeminism, help to elucidate how women's interactions with the environment can influence their health and well-being in a variety of ways.

Encouraged by feminist movements of the 1970s, many activists and researchers began to consider the role of feminist perspectives in nature-society relationships (e.g. Mies and Shiva 1993; Rocheleau et al. 1996). Feminist political ecology is a feminist approach to political ecology, where gender becomes a main category of analysis alongside a more foundational focus on the role of political and economic factors in shaping resources use and degradation. Feminist political ecology as a field is also concerned with epistemological considerations involving nature, power, and knowledge production (Rocheleau et al. 1996; Elmhirst 2011). Here, we focus on the aspects of the theory that are most relevant to environmental dimensions.

Feminist political ecologists draw on thinking in political-economy to argue that women and the environment endure shared oppression stemming from capitalism which embodies patriarchal priorities and structures (e.g. Mies and Shiva 1993; Rocheleau et al. 1996). Women and the environment share reproductive roles in the economics of uneven development. Nature is often portrayed as "feminine" and women are more commonly associated with nature. Western approaches have historically pitted man against nature, where man's ability for reason and logic allow for the domination of nature, and therefore ultimately the feminine (Plumwood 1993).

Fundamental to this perspective is the idea that men and women have different relationships to the environment because of gender roles. Socially-constructed gender roles represent an important factor in determining responsibilities and access to resources, especially in less-developed countries where people tend to be more directly reliant on the environment for meeting daily needs (Agarwal 1997; Hovorka 2006). For example, women are typically responsible for taking care of the household and children, as well as the bulk of the cooking, harvesting, and growing of food, including fetching water. Women are burdened with a disproportionate share of duties that require gathering or managing natural resources for subsistence. Conversely, men are more likely to have employment or activities 
outside of the home, or manage agricultural and livestock resources that are income-generating (Agarwal 1997; Hovorka 2006; Rocheleau et al. 1996). Even as less-developed countries are becoming more urbanized, women still hold these gendered positions, and assume the primary responsibility of taking care of the household and acquiring food and water in more urban areas (Hovorka 2006). Even in cities or peri-urban settlements in developing countries, some household resources are often still collected or harvested, such as on public river banks or lakeshores, or "backyard" gardens.

Feminist political ecology does not view gender role differences as being biologicallydetermined. Rather, they are derived from social constructs of gender, which vary depending on class, race, location, and culture, and may change over time and between individuals and societies (Rocheleau et al. 1996). Indeed, some ecofeminist frameworks have been critiqued as being essentialist or universalizing in their constructions of women. In emphasizing intersectionality and the importance of interlocking processes of differentiation including gender, race, ethnicity, class, and livelihood, feminist political ecology frameworks now seek to account more inclusively for the ways systems of power articulate across different groups in time and place.

Thus, in feminist political ecology, gender represents a critical dimension, in addition to class, race, culture and other factors in shaping environmental relations and gender roles that condition interactions with the environment. Nonetheless, feminist political ecologists stress the continuing relevance of gender as a key variable due to the continued neglect of women as environmental agents and managers. Not only are environment and social patterns gendered, but also certain environmental problems have particularly negative effects on women (e.g. Tierney 2019; WHO 2018). For example, disasters or environmental changes that impact women's ability to gather or access food may lead to risky sexual behaviors that increase their vulnerability to devastating diseases like HIV. The potential links between droughts, food insecurity, and the burden of HIV among women will be explored in more detail below, but foundational ideas about the gendered responsibilities of food production and managing environmental resources from feminist political ecology remain as a relevant theoretical grounding for these ideas and the underlying role of environmental decline in creating gendered vulnerabilities to disease.

\section{Climate Change, Droughts and Food Insecurity}

Globally, droughts have affected more people in the last four decades than any other natural hazard (FAO 2020). Droughts are a complex environmental phenomenon with varying levels of intensity, duration, and scope, though they often are described as a "creeping disaster" due to their slow onset and longer duration in comparison to other disasters (CRED 2016; FAO 2020). These characteristics cause droughts to have a major impact on people's livelihoods in a number of ways. For example, droughts are commonly linked with massive famines, forced migration, civil unrest, and underdevelopment (CRED 2016; FAO 2020). While all countries suffer from hazards such as droughts, such events in less-developed countries tend to be disproportionately and acutely devastating due to the vulnerability of poor populations (e.g. Tierney 2019). A disaster marks the interface between an extreme geological or weather event and the vulnerability of populations who are unable to cope with it. The extent of vulnerability or the severity of the disaster is determined by social conditions, systems of power, and inequality and poverty (Tierney 2019; Wisner et al. 2004). In disasters literature, vulnerability is commonly defined as the conditions faced by 
people that impact their ability to prepare for, avoid, cope with, or recover from hazards (e.g. Tierney 2019; Wisner et al. 2004). Indeed, political ecology and world-systems frameworks emphasize unequal power relations between rich and poor populations that distribute a disproportionate burden of the effects of climate change on the poor globally, despite that affluent populations are most responsible for climate change (e.g. Tierney 2019).

A number of sources link the increased occurrence and suffering from droughts over time with global climate change (e.g. FAO 2020; Lewis 2017; Marvel et al. 2019; NOAA 2020). When considering the relationship between climate change and drought, it is important to distinguish between weather and climate, as well as different kinds of droughts. Weather describes atmospheric conditions over a short period of time, while climate is how the atmosphere performs over long periods of time (UCS 2014). A meteorological drought occurs when there is a lack of rainfall creating a dry period (NOAA 2020). Hydrological droughts result when decreased precipitation affects streamflow, soil moisture, reservoir and lake levels, and groundwater recharge (NOAA 2020). These conditions can lead to a third kind of drought, agricultural droughts, where a lack of water resources impacts the production of crops or the health of livestock. Agricultural droughts can occur for a variety of reasons, including low precipitation, the timing of water availability, or decreased access to reserve water supplies (NOAA 2020).

While individual drought periods can be understood as discrete weather events, as temperatures have continued to warm above average levels over the past century, the prevalence, intensity, and duration of droughts have increased in many regions (e.g. FAO 2020; Lewis 2017; Marvel et al. 2019; UCS 2014). Climate changes facilitating rising temperatures encourage droughts in a number of ways, including more precipitation falling as rain rather than snow, earlier snow melts, and increased evaporation and transpiration (FAO 2020; UCS 2014). Thus, the direct risks of hydrological and agricultural drought increase as global temperatures rise. Climate change is also impacting the amount and timing of rainfall, including less rainfall in many regions, leading to all three kinds of drought (FAO 2020).

Drought ranks as the most common cause of severe food shortages in less-developed countries, and represents one of the most important causes of food insecurity and famine (FAO 2020; Sam et al. 2019). Agriculture is the first sector affected when a drought hits, and also represents the most affected sector in less-developed countries, absorbing up to 80 percent of all direct impacts of droughts (FAO 2020). Certainly, a lack of rainfall or water supplies impacts food production and, therefore, livelihoods and physical well-being, particularly in poor countries that are most dependent on subsistence and local food sources and more likely to lack the infrastructure (e.g. irrigation, man-made reservoirs) to mitigate the effects of drought (Sam et al. 2019). Overall, livestock, crops, and fisheries represented more than 80 percent of drought-induced economic damages suffered by less-developed countries from 2005 to 2015 (FAO 2020).

Droughts affect all four dimensions of food security: availability, stability, access, and utilization (CRED 2016; FAO 2011). Consequences of drought that impact food production and supplies include the inability to cultivate crops, lower yields in both crop and livestock production, increased livestock deaths and disease, increases in insect infestation and plant diseases, damage to fish habitats, increased forest fires, and heightened soil erosion (FAO 2011). While rural livelihoods are directly or perhaps more obviously at stake (e.g. Lewis 2017), the consequences of droughts easily reach to urban areas and the global market (e.g. World Bank 2012). For example, droughts and decreased food production in rural areas can impact availability or pricing in more distant markets (FAO 2011; World Bank 2012). Thus, droughts can impact food security and access among urban residents as well 
as subsistence farmers. However, when issues with food availability arise, the most severe effects are felt among the poorest and most vulnerable, including women (e.g. Memon et al. 2018; WFP 2020).

In some countries, gender norms and sexist beliefs mean women and girls eat last, after the men and boys of the household have been fed (e.g. Lartey 2008; WFP 2020). When a crisis hits, such as a drought, women are typically the first to sacrifice their own food to ensure their children or others have enough to eat (Le Masson et al. 2016; Memon et al. 2018). Thus, while gender roles require women to be primarily responsible for acquiring food, gender inequalities mean that women often get the smallest amount of food. The World Food Program (2020) reports that 60 percent of the 821 million people who are food insecure worldwide are female.

\section{Food Insecurity, HIV Susceptibility, and Risky Sexual Behaviors}

Links between food insecurity and HIV are well-established in the literature. Many emphasize that HIV/AIDS and food insecurity constitute a vicious cycle, where food insecurity can increase biological susceptibilities to HIV, and living with HIV can also compromise one's ability to grow or access food (e.g. Gebremichael et al. 2018; Gillespie and Kadiyala 2005; Ivers et al. 2009). As our goal is to understand the drivers of the disproportional burden of HIV/AIDS among women in less-developed countries, we will focus on investigating how food insecurity enhances the likelihood of acquiring HIV.

Food insecurity can cause malnutrition which weakens the body's ability to fight illnesses and diseases (Gebremichael et al. 2018; Gillespie and Kadiyala 2005). Both macronutrient deficiencies, such as not getting enough food, and micro-nutrient deficiencies, such as lacking in certain essential minerals and vitamins, weaken the immune system and impair its ability to fight all kinds of infections, including HIV (Friis 2005; Friis and Michaelsen 1998). Malnutrition does not have to be severe for this weakening to occur; even slight deficiencies can hinder the body's ability to combat disease. Indirectly, malnutrition can lead to other infections that also put the body in a compromised position to fight off HIV exposure. For example, suffering from diseases such as malaria, schistosomiasis, sleeping sickness, or intestinal parasites can weaken the body and increase the likelihood of contracting HIV when exposed.

It is important to recognize that the association between malnutrition and HIV is layered with gender inequalities in many less-developed countries where 'girls eat last' (e.g. Lartey 2008; WFP 2020); thus, women are more likely to face the heightened infection risks associated with nutrient deficiencies in comparison to men due to socially-constructed inequalities. Social dimensions also matter; dealing with food insecurity takes time and effort, mainly on the part of women as women bear the brunt of managing household needs and environmental resources used for subsistence (e.g. Memon et al. 2018; Opondo et al. 2016). In times of hardship, women are more likely to wait longer to access health services (Gillespie and Kadiyala 2005; Hadley et al. 2012). Increases in food prices or difficulties cultivating food may also lead to decreases in young women's participation in schooling. Household finances may need to be are redirected to the most basic of needs or prioritized solely on the education of male children (e.g. Belachew et al. 2011; Momo et al. 2019). If degradation or disaster causes people to have walk farther to fetch water or grow crops further away from the homesite, it is the young women that are most likely to be required 
to stay home from school and help with additional household labor needs, given gendered norms and roles (Le Masson et al. 2016; Memon et al. 2018).

Families sometimes engage their daughters in early marriage as a coping strategy in the wake of disasters when facing issues like food insecurity, in order to earn a dowry or to have fewer mouths to feed (e.g. Ahmed et al. 2019; Opondo et al. 2016). While such strategies may be necessary to provide for the household on the whole, these responses often compromise women's access to completing secondary education and ability to negotiate for their reproductive autonomy. Therefore, food insecurity also indirectly intensifies these existing gendered inequalities that limit women's access to healthcare, education, and improved autonomy, potentially putting women in a more vulnerable position of contracting HIV (Belachew et al. 2011; Opondo et al. 2016; Tsai et al. 2012).

Transactional sex and other forms of risky sexual behavior also represent a prominent consequence of food insecurity for women. Indeed, many studies find that when faced with hunger, deprivation, or being unable to provide for basic household needs, women are often obligated to engage in formal or informal transactional sexual relationships in order to get food or money. This type of transactional sex is commonly referred to as 'sex for basic needs' (e.g., Miller et al. 2011; Stoebenau et al. 2016; Weiser et al. 2007). Indeed, a number of studies conducted in poor countries emphasize that food insecurity produces more dangerous sexual circumstances for women, including inconsistent condom use, abusive relationships, transactional sex, or participation in commercial sex work (e.g. Masa et al. 2019; Pascoe et al. 2015; Pellowski et al. 2018; Tsai et al. 2012; Tsai and Weiser 2014; Weiser et al. 2007).

It is important to acknowledge that social behaviors like transactional sex are not limited to less-developed countries; many women in affluent countries as well engage in what could be considered transactional relationships. However, transactional sexual relationships, especially those motivated by basic needs such as food, are particularly common in poorer countries where women face life-threatening hardships due to extreme poverty and heightened gender disparities. In poorer countries with elevated HIV prevalence rates, transactional sex poses a much greater risk to health because the chance of contracting HIV is magnified.

Women who engage in transactional sex relationships or are married off as teenagers in the face of hardship are more likely to be involved with older men who are wealthier and can provide better payments or gifts (e.g. Ahmed et al. 2019; Mojola 2014). The age gap between men and women is important in explaining women's distinct vulnerabilities to HIV in less-developed countries. Older, more affluent men tend to have the highest rates of HIV infection demographically in developing countries, as they have had decades of sexual partners and have the economic means to have supported multiple sex partners over the years (Mojola 2014; Muula 2008). In contrast, HIV rates among young men in their late teens and twenties tend to be relatively low in less-developed countries, as most men in this age group have unstable income opportunities and face challenges in supporting a girlfriend or sex partner (Mojola 2014; Muula 2008; UNAIDS 2017). Condom use is also very low in transactional sex relationships and women in less-developed countries have less ability to negotiate condom use when there is a significant age gap (Mojola 2014). Forced sex is also more common in relationships with notable age gaps, and younger women entering first marriages who have not yet had sexual debut are more likely to experience tearing during intercourse, further elevating HIV exposure when involved with an HIV-positive partner (Muula 2008).

In linking these literatures, food insecurity is likely to impact women's disproportionate vulnerability to HIV in a number of ways, including the greater likelihood of having 
nutrient deficiencies that increase biological susceptibilities of infection, as well as through social mechanisms that reduce women's access to education or healthcare or that encourage women's participation in risky sexual relationships, such as transactional sex. We now turn to a discussion of our key predictions and methods.

\section{Predictions}

In this study we test a number of important interrelationships involving suffering from drought, food insecurity, women's socio-health status, and women's percentage of the population that are HIV-positive, as well as additional social, economic, and cultural predictors. In particular, we focus on formally predicting that less-developed countries with increased suffering from droughts have elevated rates of food insecurity; we predict that food insecurity, in turn, has direct links to the percentage of the adult population living with HIV that are female, as well as indirect links through women's socio-health status and contraceptive use.

\section{Methods}

To assess the impact of drought on the portion of the adult population living with HIV that are women, we utilize structural equation modeling (SEM). This method is most appropriate because it allows us to model a combination of social, economic, and environmental factors that together shape the risk context in which women are uniquely vulnerable to HIV. Our utilization of SEMs allows us to explicitly model direct and indirect pathways, properly incorporating prior qualitative and quantitative studies in order to model the interconnections involving drought, food insecurity, women's status, and disease. This would not be possible using traditional regression direct-effects approaches.

Additionally, the utilization of a maximum likelihood (ML) missing value routine in SEMs reduces issues of missing data, a common problem especially in cross-national research. A maximum likelihood (ML) missing value routine predicts pathway coefficients using all available data points. Cases with missing data are simply dropped from those pathway estimations, but still used for others when the data are available (Arbuckle 1996). With the ML missing value routine, the estimates are consistent and efficient under the condition that the data are missing at random (MAR). This is an easier condition to meet than missing completely at random (MCAR), which is required for other common methods of dealing with missing data, like listwise deletion. Thus, SEM allows us to maximize our sample of countries by retaining cases that might be missing data on one or two control variables included in the models under a less rigorous set of assumptions regarding the missingness of the data (Arbuckle 1996).

A further advantage of SEMs is the ability to model latent factors (e.g. Bollen 1989), such as multi-faced concepts like health infrastructure and women's socio-health status. To test that access to clean water, the number of health workers, and secondary schooling represent components or characteristics that measure underlying health infrastructure, and to test that female secondary schooling, fertility rates, and births attended represent components of women's socio-health status, we initially construct a confirmatory factor analysis (CFA) of these measures, analyzing the overall and component measures of fit. By empirical standards, we find evidence at both the component and overall model levels 


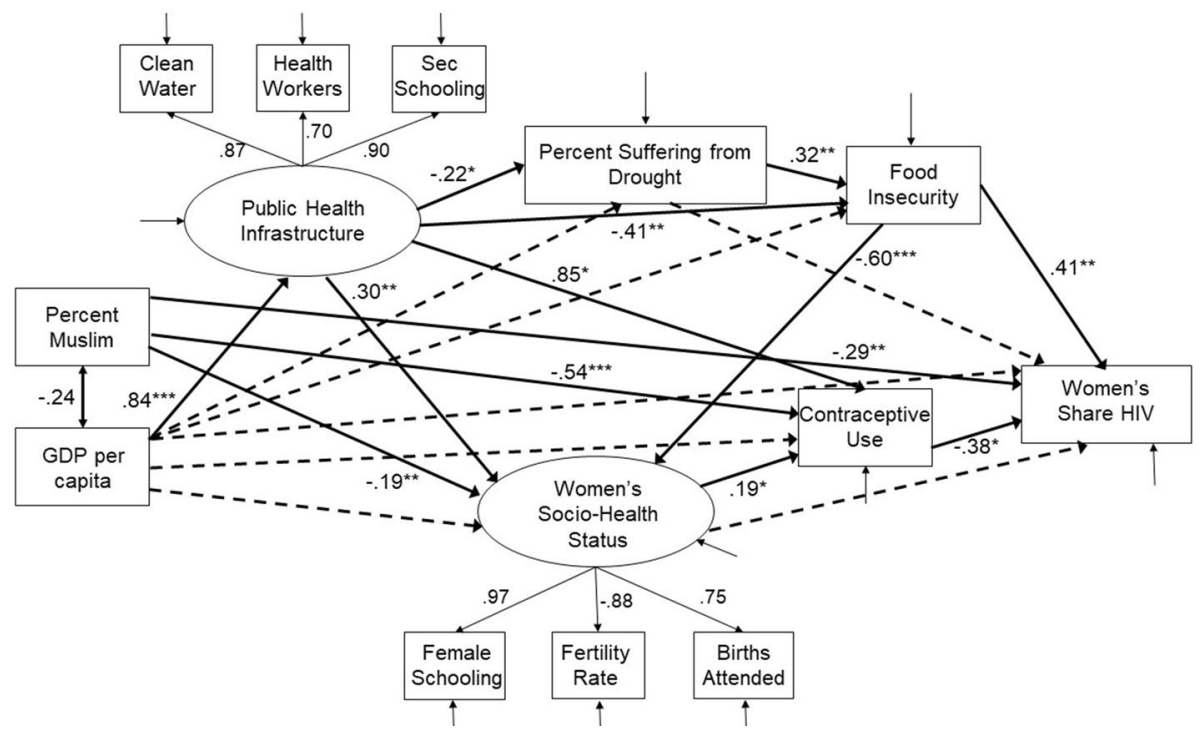

Fig. 1 SEM predicting the percent of the population living with HIV who are women, saturated model

to support our prediction that these indicators can be used to measure health infrastructure and women's socio-health status, respectively.

Conducting a SEM requires 4 steps: model specification, estimation, identification, and determination of model fit (e.g. Bollen 1989). To specify our model, we create path diagrams to represent our hypothesized theoretical models of the interconnections between droughts, food insecurity, women's socio-health status, and the percentage of the population living with HIV that are female. To estimate our models, we used both AMOS and Mplus. For identification in SEMs, it is important that the models can in theory and practice be estimated with observed data. As described in more detail below, we include a wide range of environmental, social, economic, and cultural indicators based on prior research and theory related to our topics of interest to enhance theoretical identification. To ensure statistical estimation, as mentioned above, we utilized SEM software in two statistical packages, AMOS and Mplus, where the path diagrams displayed in Figs. 1 and 2 all estimated normally. The last step concerns meeting thresholds for model fit. In SEMs, model fit measures allow researchers to gauge the fit of the model as a whole to the data provided and compare equally plausible models (Bollen 1989). The model fit statistics for both SEMs are well within acceptable range and demonstrate excellent fit to the data, as reported below with our results.

\section{Sample}

Our sample includes all less-developed countries where data is available for our key outcome of interest, women's HIV burden. We restrict our sample only to less-developed countries due to our focus on gender, disasters, and HIV. According to the World Bank's income classification, less-developed countries are those that occupy the lower three 


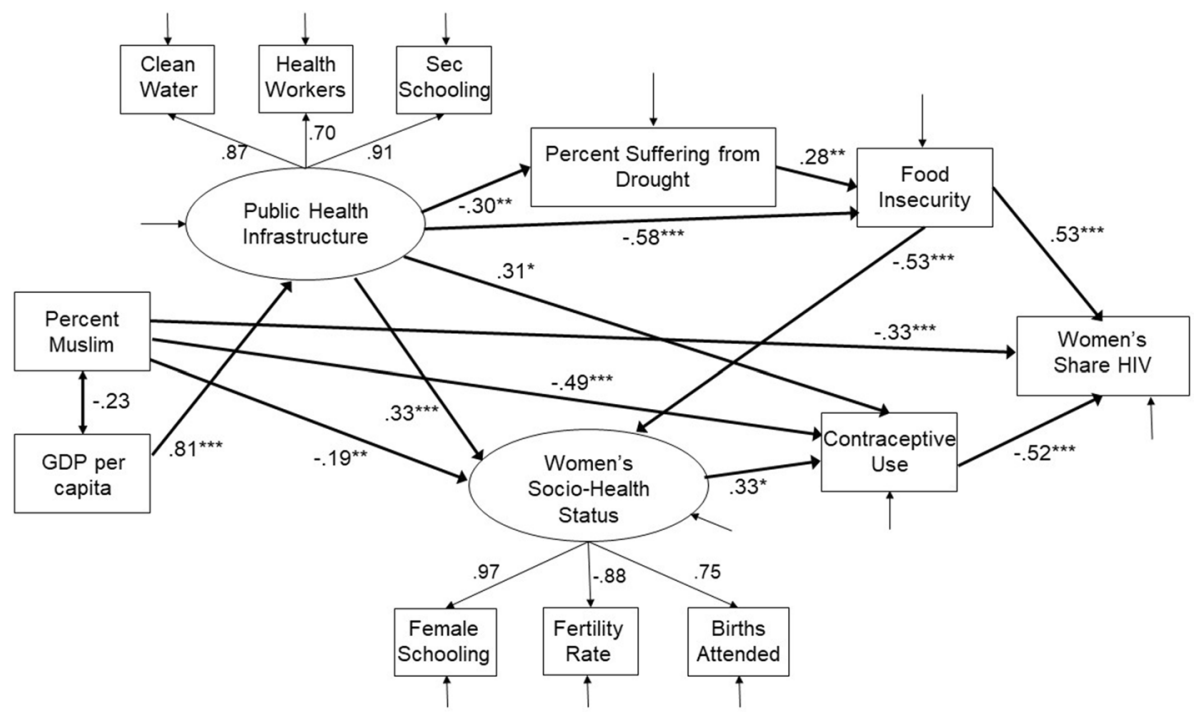

Fig. 2 SEM predicting the percent of the population living with HIV who are women. Notes standardized coefficients flagged $* * * p<0.001, * * p<0.01, * p<0.05$, (two-tailed tests)

quartiles of GDP per capita in 2010 (World Bank 2017). Thus, our sample includes 91 lessdeveloped countries, as noted in Table 1.

\section{Key Dependent Variable}

Women's Percent of HIV. We employ the percentage of the adult population living with HIV that are women as the key outcome variable. This variable captures the percentage of the population aged 15 or older living with HIV who are female. This data was obtained from the World Bank (2019), who includes these data from the Joint United Nations Programme on HIV/AIDS or UNAIDS. As emphasized above, we employ a measure of the female HIV burden as a percentage of cases among women rather than an overall prevalence measure, as the former more appropriately operationalizes gender inequalities between men and women in the burden of HIV (e.g. Austin and Noble 2014). Our focus is on explaining some of the reasons behind the rising HIV burden among women in particular; thus, a measure that compares the gender distribution in cases between women and men is the most appropriate to use. ${ }^{2}$

\footnotetext{
${ }^{2}$ We did however examine additional models using women's HIV prevalence; the findings surrounding droughts, food insecurity, and women's HIV prevalence remained robust. However, some of the relationships involving women's socio-health status, contraceptive use, and women's HIV prevalence were not as salient as those presented here. This again reflects the nature of the measure used and lends further support for using data on the percentage of the adult population living with HIV who are women to better capture gender inequalities in the disease.
} 
Table 1 Countries included in the analysis $(\mathrm{N}=91)$

\begin{tabular}{|c|c|c|}
\hline Afghanistan & Eswatini & Nepal \\
\hline Algeria & Ethiopia & Niger \\
\hline Angola & Gambia, The & Nigeria \\
\hline Armenia & Georgia & Pakistan \\
\hline Bangladesh & Ghana & Papua New Guinea \\
\hline Belize & Guatemala & Paraguay \\
\hline Benin & Guinea & Peru \\
\hline Bhutan & Guinea-Bissau & Philippines \\
\hline Bolivia & Guyana & Rwanda \\
\hline Bosnia and Herzegovina & Haiti & Senegal \\
\hline Botswana & Honduras & Serbia \\
\hline Burkina Faso & Indonesia & Sierra Leone \\
\hline Burundi & Jamaica & Somalia \\
\hline Cabo Verde & Jordan & South Africa \\
\hline Cambodia & Kenya & South Sudan \\
\hline Cameroon & Kyrgyz Republic & Sri Lanka \\
\hline Central African Republic & Lao PDR & Sudan \\
\hline Chad & Lesotho & Syrian Arab Republic \\
\hline Colombia & Liberia & Tajikistan \\
\hline Comoros & Madagascar & Tanzania \\
\hline Congo, Dem. Rep & Malawi & Togo \\
\hline Congo, Rep & Malaysia & Tunisia \\
\hline Costa Rica & Mali & Uganda \\
\hline Cote d'Ivoire & Mauritania & Ukraine \\
\hline Cuba & Mauritius & Uzbekistan \\
\hline Djibouti & Moldova & Vietnam \\
\hline Dominican Republic & Mongolia & Yemen, Rep \\
\hline Ecuador & Montenegro & Zambia \\
\hline Egypt, Arab Rep & Mozambique & Zimbabwe \\
\hline El Salvador & Myanmar & \\
\hline Eritrea & Namibia & \\
\hline
\end{tabular}

\section{Independent Variables}

Percent suffering from drought and food insecurity represent two key variables in our analysis. Percent suffering from drought represents the percentage of the population affected, injured, left homeless, or killed due to a drought from 2010 to 2016. Those "affected" by drought include people requiring immediate assistance, such as those lacking basic survival needs for food, water, shelter, sanitation and medical assistance. These data come from the EM-DAT Database (2019). For a disaster to be in the database, at least one of the following conditions must be met: ten or more people reported killed, one hundred or more people reported affected, a declaration of a state of emergency, or a call for international assistance. To create the measure of percent of people suffering from drought, we first divided the number of people affected, injured, left homeless, or killed for each nation in a given year due to drought by the total population, using total population data obtained from the World Bank (2019) for the same year. We then averaged the proportions for each 
year from 2010 to 2016, thereby avoiding idiosyncratic findings that might emerge from a single major event in a given year.

We measure food insecurity using data from the Food and Agriculture Organization (2019) on the prevalence of moderate or severe food insecurity. This measure is an estimate of the percentage of people in the population who live in households classified as moderately or severely food insecure. The measure is calculated using data collected with the Food Insecurity Experience Scale or a compatible experience-based food security measurement questionnaire.

In any cross-national analysis it is important to control for GDP per capita. Level of economic development is likely to predict a number of other relevant indicators in the model, such as health infrastructure. Gross domestic product (GDP) per capita represents the total annual output of a country's economy divided by its population, measured in current international dollars (World Bank 2019). More specifically, GDP per capita is the total market value of all final goods and services produced in a country in a given year, equal to total consumer, investment, and government spending, divided by the mid-year population. It is converted into current international dollars using Purchasing Power Parity (PPP) rates, providing a standard measure that allows for comparisons of real price levels between countries.

Previous studies demonstrate that nations with large Muslim populations are found to have lower HIV prevalence (e.g. Austin and Noble 2014). This relationship may be due to strict religious tenets dictating conservative sexual norms that protect against extramarital sex, for example. Thus, we include a measure of percent Muslim as an important cultural factor potentially impacting women's HIV and other aspects, such as contraceptive use. Percent Muslim refers to the percentage of the national population that identifies Islam as their religious affiliation. This measure was obtained from the Pew Research Center's report on World Muslim Population by Region and Country (2009).

Provisions for health infrastructure are very important in predicting health outcomes and suffering from disaster (e.g. Clark and Snawder 2020; Tierney 2019). Thus, we include measures for clean water, number of health workers, and secondary schooling. Percent access to clean water refers to the percentage of the population using an improved drinking water source (World Bank 2019). Improved drinking water sources include piped water located inside the user's dwelling, plot, or yard, and other improved drinking water sources, such as public taps or standpipes, tube wells or boreholes, protected dug wells, protected springs, and rainwater collection. We measure the number of trained health workers using data from the World Bank (2019) on the number of physicians per 100,000 . This measure includes nurses, midwives, generalists, and specialist medical practitioners. To measure secondary school participation, we utilize data on gross secondary school enrollments, which is a ratio between the total enrollment regardless of age to the age group that officially corresponds to secondary level education (World Bank 2019).

Many cross-national studies emphasize the importance of indicators related to women's status in predicting women's HIV (e.g. Austin and Noble 2014; Austin et al. 2017). We therefore include several measures of women's socio-health status, including women's participation in schooling, the fertility rate, and the percentage of births attended by a skilled health worker. To measure women's secondary schooling, we utilize the gross enrollment measure, which is total enrollment of females, regardless of age, to the female population of the age group that officially corresponds to secondary level education (World Bank 2019). Alongside women's schooling, fertility rates also capture key aspects of female empowerment, as more empowered women are able to gain control of 
their reproductive rights and typically have fewer children. The fertility rate is an estimate of the number of children an average woman would have if current age-specific fertility rates remained constant during her reproductive years (World Bank 2019). Percent of births attended by skilled health staff captures women's specific access to healthcare. Births attended represents the percentage of deliveries attended by personnel trained to give the necessary supervision, care, and advice to women during pregnancy, labor, and the postpartum period, to conduct deliveries on their own, and to care for newborns (World Bank 2019).

We also include a measure of contraceptive use, as some methods of contraception, such as condoms, can directly protect against HIV transmission. Furthermore, use of any contraceptive method signifies increased levels of reproductive autonomy or empowerment for women that can protect against HIV transmission in other ways. We anticipate that women's socio-health status is positively correlated with use of contraceptives. The contraceptive use rate is the percentage of women ages 15-49 who are practicing, or whose sexual partners are practicing, any form of contraception (World Bank 2019).

Given the focus on HIV/AIDS in the analysis, we also tested for the influence of ARTs or antiretroviral therapies, which can extend the life and quality of life of HIV-positive individuals and thus have a powerful influence on HIV prevalence rates. We did not find any significant influence of ARTs on the proportion of HIV cases among women in our analyses. This is likely due to the manner in which our outcome is measured, as a percentage of HIV/AIDS between women and men rather than a prevalence rate. The lack of significance for ARTs in the models suggests that use of such interventions is not impacting the distribution of disease among men versus women.

To help address conditions of causality, the variables are time-ordered, where the independent variables are measured prior to the dependent variables. Specifically, the percentage of HIV cases among women measured for the year 2018, contraceptive use, female schooling, the fertility rate, and births attended are all measured in 2017 , food insecurity is measured in the year 2016, and GDP per capita, the health infrastructure measures, and Percent Muslim are all measured for the year 2010. We measure droughts as an average from 2010 to 2016 as described above.

\section{Results}

We first include Table 2, that displays the correlation matrix and univariate statistics for all variables used in the analyses. Some of the correlations are rather high, such as the correlation between female schooling and fertility rates, demonstrating the importance of using a technique like SEMs that includes the ability to create latent constructs and model interrelationships, thus lessening potential biases created by multicollinearity (e.g., Bollen 1989).

Figures 1 and 2 present the SEM results predicting the percentage of HIV cases among women. Figure 1 represents a saturated model, testing all paths or interrelationships based on prior research and theory; Fig. 2 represents a trimmed model, where nonsignificant relationships are dropped. In Figs. 1 and 2, solid lines denote statistically significant pathways and standardized regression coefficients are flagged for statistical significance. Non-significant pathways are denoted by dashed lines. The model fit statistics for both SEMs in Figs. 1 


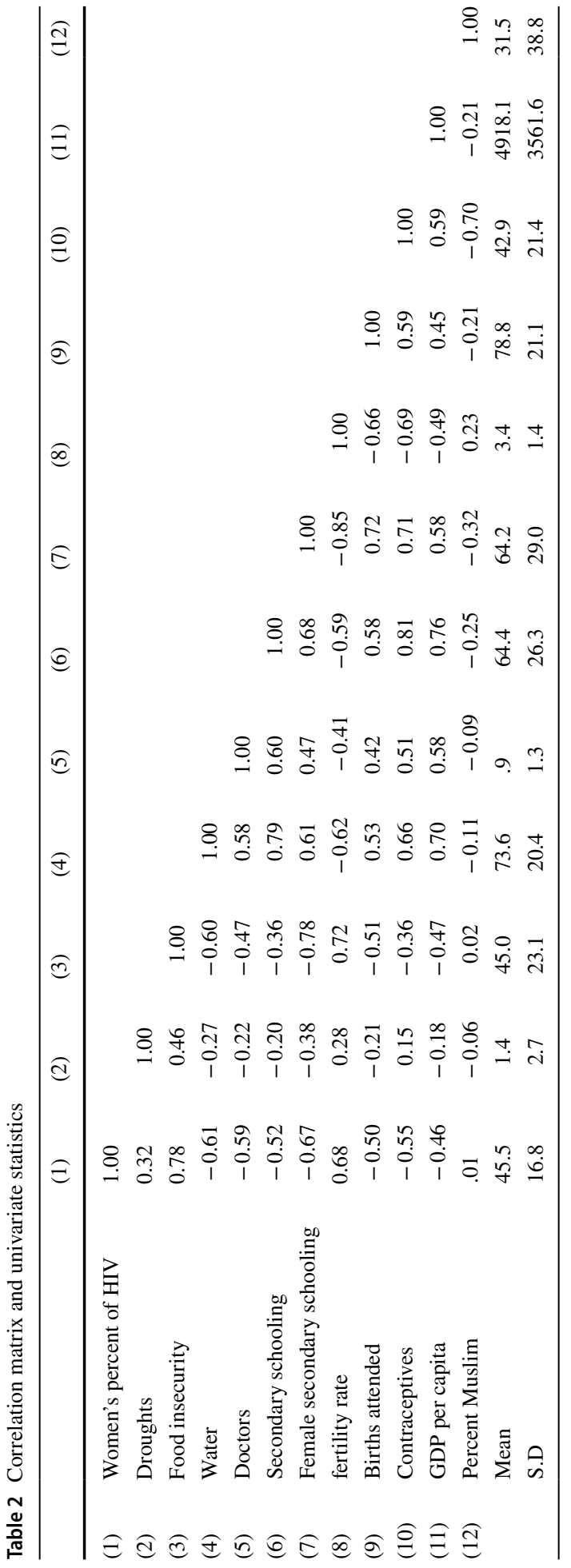


and 2 are in appropriate range and demonstrate an excellent fit of the models to the data ${ }^{3}$; thus, for parsimony and relevance, we follow conventional practices in SEM and focus our interpretation on the more parsimonious model presented in Fig. 2.

In addition to the path diagram in Fig. 2, we provide unstandardized regression coefficients, standardized regression coefficients, and standard error estimates for the model displayed in Table 3. ${ }^{4}$ Looking at the results presented graphically in Fig. 1, we find preliminary support for our predictions surrounding suffering from droughts, food insecurity, and women's burden HIV in less-developed countries. Specially, we find that less-developed countries with elevated suffering from droughts have increased levels of moderate and severe food insecurity (0.28), and food security directly increases the percentage of HIV cases among women (0.53). Our results also suggest that food insecurity has indirect impacts through women's socio-health status. Specifically, we find food insecurity negatively impacts women's sociohealth status, including education, fertility, and access to medical care $(-0.53) .{ }^{5}$ Women's socio-health status in turn influences use of contraceptives $(0.33)$, which is directly associated with lowering the percent of the adult population living with HIV who are women $(-0.52)$ in less-developed countries. This set of findings confirms our central hypotheses.

In addition to the important relationships surrounding droughts, food insecurity, women's status, contraceptive use, and women's HIV, a number of other variables are also salient in influencing these relationships. For example, in addition to women's socio-health status, public health infrastructure, made up of percent access to clean water, number of health workers, and participation in secondary schooling, (0.31) and percent Muslim (-0.49) are significant in predicting contraceptive use in less-developed countries. Public health infrastructure $(0.33)$ and percent Muslim (- 0.19) are also salient in influencing women's socio-health status. While percent Muslim seems to have a harmful impact on women's HIV through negative influences on contraceptive use and women's socio-health status, percent Muslim is also directly associated with lower proportions of HIV among women ( -0.33$)$. Our results reveal that public health infrastructure of water, doctors, and schooling are important in reducing suffering from droughts $(-0.30)$ in less-developed countries, and that countries with higher levels of economic development, or GDP per capita, have improved public health infrastructure (0.81).

While the path diagrams begin to demonstrate the role of factors like drought or food insecurity in explaining women's disproportionate vulnerability to HIV, it is impossible to evaluate or compare the relevance of predictors that have indirect influences. Thus, we also

\footnotetext{
3 In accordance with standards typical for this empirical tradition, for the model displayed in Fig. 1, the chi-square test statistic is nonsignificant $(\chi 2=42.229$ with 39 degrees of freedom), the values of the Incremental Fit Index (.994), Tucker-Lewis Index (.987), and the Confirmatory Fit Index (.994) all exceed .90, and the root mean squared error of approximation (RMSEA) value (.030) is below .05. The SEM displayed in Fig. 2 also meets these thresholds; the chi-square test statistic is nonsignificant ( $\chi 2=49.816$ with 46 degrees of freedom), the values of the IFI (.993), TLI (.987), and the CFI (.992) all exceed .90, and the RMSEA value (.030) is below .10. Together, these fit indices demonstrate excellent model fit to the data and permit interpretation of the pathway coefficients.

4 These results are also available for the model presented in Fig. 1 from the authors upon request.

5 We also considered that women's status predicts food insecurity, and tested models with this causal relationship reversed. We obtained model fit statistics in the appropriate range and path estimates that are largely consistent with the models presented here. However, the model fit statistics for the models where food insecurity predicts women's socio-health status were far superior. We also draw on prior research and theory which discusses how food insecurity can impact women's access to schooling and medical care, or lead to early marriage and earlier and higher fertility.
} 
Table 3 Regression estimates for SEM equations predicting the percent of the population living with HIV who are women

\begin{tabular}{llccc}
\hline Regression path & B & SE(B) & \multicolumn{1}{c}{$\hat{\beta}$} \\
\hline 1 & Health infrastructure $\rightarrow$ Water & $0.874^{* * *}$ & 0.035 & 1.000 \\
2 & Health infrastructure $\rightarrow$ Doctors & $0.701^{* * *}$ & 0.066 & .053 \\
3 & Health infrastructure $\rightarrow$ Secondary schooling & $0.912^{* * *}$ & 0.033 & 1.348 \\
4 & Women's socio-health status $\rightarrow$ Births attended & $0.746^{* * *}$ & 0.058 & 1.000 \\
5 & Women's socio-health status $\rightarrow$ Female Sec schooling & $0.968^{* * *}$ & 0.022 & 1.757 \\
6 & Women's socio-health status $\rightarrow$ Fertility rate & $-0.883^{* * *}$ & 0.031 & -0.077 \\
7 & Health infrastructure $\rightarrow$ Women's socio-health status & $0.327^{* *}$ & 0.111 & 0.288 \\
8 & GDP per capita $\rightarrow$ Health infrastructure & $0.814^{* * *}$ & 0.045 & 0.397 \\
9 & Women's socio-health status $\rightarrow$ Contraceptive use & $0.333^{*}$ & 0.157 & 0.459 \\
10 & Health infrastructure $\rightarrow$ Contraceptive use & $0.310^{*}$ & 0.169 & 0.377 \\
11 & Health infrastructure $\rightarrow$ Droughts & $-0.300^{* *}$ & 0.103 & -0.045 \\
12 & Food insecurity $\rightarrow$ Women's socio-health status & $-0.594^{* * *}$ & 0.095 & -0.407 \\
13 & Percent Muslim $\rightarrow$ Contraceptive Use & $-0.486^{* * *}$ & 0.097 & -0.272 \\
14 & Droughts $\rightarrow$ Food insecurity & $0.280^{* *}$ & 0.097 & 2.430 \\
15 & Food insecurity $\rightarrow$ Women's percent of HIV & $0.527^{* * *}$ & 0.101 & 0.382 \\
16 & Percent Muslim $\rightarrow$ Women's percent of HIV & $-0.326^{*}$ & 0.129 & -0.140 \\
17 & Contraceptives $\rightarrow$ Women's percent of HIV & $-0.523^{* *}$ & 0.153 & -0.401 \\
18 & Health infrastructure $\rightarrow$ Food insecurity & $-0.578^{* * *}$ & 0.093 & -0.743 \\
19 & Percent Muslim $\rightarrow$ Women's socio-health status & $-0.190^{* *}$ & 0.072 & -0.077 \\
\hline
\end{tabular}

Standardized coefficients flagged $* * * p<0.001, * * p<0.01,{ }^{*} p<0.05$, (two-tailed tests)

calculate and compare the total, direct, and direct effects, displayed below in Table 4. The results presented in Table 4 depict that the percent of the population suffering from droughts and food insecurity are both significant in their total overall impact on the percent of the adult population living with HIV who are women. In particular, the impact of droughts is entirely indirect (0.176), but still significant in the overall impact on women's percent of HIV. Notably, the total influence of food insecurity is quite large (0.630), accounted for by both the direct and indirect influences on women's percentage of HIV cases through reducing women's sociohealth status and contraceptive use. Importantly, the impacts of GDP per capita $(-0.517)$, health infrastructure $(-0.636)$, and women's socio-health $(-0.174)$ on the percentage of HIV cases among women are all indirect, but still significant. The results presented in Table 4 also clearly show that the positive indirect and negative direct effects of Percent Muslim cancel out, leaving this variable to have no overall impact on the percent of the adult population living with HIV who are women in less-developed countries.

Taken together, the results demonstrate that suffering from drought puts women at disproportionate risk of acquiring HIV in less-developed countries through increased food insecurity. Food insecurity has a robust direct and indirect influence on the percent of the adult population living with HIV who are women in less-developed countries. Food insecurity reduces women's socio-health status, which in turn, is associated with lower contraceptive use. A number of other indicators, including GDP per capita and public health infrastructure, have indirect links to women's percentage of HIV through influences on suffering from droughts, women's socio-health status, and contraceptive use. 
Table 4 Direct, indirect, and total effects of the predictors of the percent of the population living with HIV who are women

\begin{tabular}{|c|c|c|c|}
\hline \multirow{2}{*}{ Predictor } & \multicolumn{3}{|c|}{ Women's percent of HIV } \\
\hline & Direct & Indirect & Total \\
\hline \multirow[t]{3}{*}{ Droughts } & - & $0.176^{* *}$ & $0.176^{* *}$ \\
\hline & - & $(0.063)$ & $(0.063)$ \\
\hline & - & [1.110] & [1.110] \\
\hline \multirow[t]{3}{*}{ Food insecurity } & $0.527^{* * *}$ & $0.103^{+}$ & $0.630^{* * *}$ \\
\hline & $(0.101)$ & $(.056)$ & $(.090)$ \\
\hline & {$[.382]$} & {$[.075]$} & {$[.457]$} \\
\hline \multirow[t]{3}{*}{ GDP per capita } & - & $-0.517^{* * * *}$ & $-0.517^{* * *}$ \\
\hline & - & $(0.064)$ & $(0.064)$ \\
\hline & - & {$[-0.235]$} & {$[-0.235]$} \\
\hline \multirow[t]{3}{*}{ Percent Muslim } & $-0.326^{*}$ & $0.287^{* *}$ & -0.039 \\
\hline & $(0.129)$ & $(0.105)$ & $(0.075)$ \\
\hline & {$[-0.140]$} & {$[0.124]$} & {$[-0.017]$} \\
\hline \multirow[t]{3}{*}{ Health infrastructure } & - & $-0.636^{* * *}$ & $-0.636^{* * *}$ \\
\hline & - & $(0.066)$ & $(0.066)$ \\
\hline & - & {$[-0.593]$} & {$[-0.593]$} \\
\hline \multirow[t]{3}{*}{ Women's socio-health status } & - & $-0.174^{*}$ & $-0.174^{*}$ \\
\hline & - & $(0.091)$ & $(0.091)$ \\
\hline & - & {$[-0.184]$} & {$[-0.184]$} \\
\hline \multirow[t]{3}{*}{ Contraceptive use } & $-0.523^{* *}$ & - & $-0.523^{* *}$ \\
\hline & $(0.153)$ & - & $(0.153)$ \\
\hline & {$[-0.401]$} & - & {$[-0.401]$} \\
\hline
\end{tabular}

Standardized coefficients flagged $* * * p<0.001, * * p<0.01, * p<0.05$, (two-tailed tests); standard errors in parentheses; unstandardized coefficients in brackets

\section{Conclusion}

Droughts are notable climate-related events that impact more people globally than any other type of disaster, and models predict increased severity of droughts in years to come (FAO 2020). By 2025, 1800 million people are expected to be living in countries or regions with "absolute" water scarcity, and two-thirds of the world population could be under "stress" conditions (FAO 2020). As the consequences of droughts, including food insecurity, become intensified, understanding the myriad of ways these forces influence disease vulnerabilities will be of upmost importance. This paper adds to the growing body of literature on women's HIV in less-developed countries, making a unique contribution by looking at the upstream or indirect causes of vulnerability, including the influence of droughts and food insecurity alongside other cultural, social, and economic predictors.

Overall, we find that there is a significant indirect relationship between suffering from drought and the percent of the adult population living with HIV who are women in less-developed countries, which is mediated by food insecurity. Food insecurity itself has both direct and indirect associations to women's percentage of HIV. These results speak to the case study literature discussed that focuses on direct vulnerabilities through nutrient deficiencies which women are more likely to face, as well as the social 
vulnerabilities to disease that are created when women are forced to engage in risky sexual behaviors, drop out of school, deprioritize their health, or become married at a young age. To help explain the challenges women face, we draw on feminist political ecology and ecofeminist assertions that explore the unique ways that environmental degradation and decline impact women (Rocheleau et al. 1996). As women are most responsible for securing food and other basic essentials for the household in less-developed countries, they may sacrifice themselves or be forced to sacrifice themselves in a myriad of ways to ensure their families' needs are met.

The use of SEMs allowed us to examine some of these mechanisms in a cross-national, comparative analysis. In addition to the direct and indirect impacts surrounding drought, food insecurity, and women's burden HIV, the ability to model both direct and indirect effects uncovered important results with other indicators, such as GDP per capita. For example, we find that level of economic development has no significant direct links to women's HIV or other key predictors in the model, such as suffering from drought or food insecurity. Rather, GDP per capita acts indirectly through investments in public health resources like drinking water, doctors, and schooling, to protect people from drought, prevent hunger, and reduce gendered vulnerabilities to disease. Thus, economic gains do not automatically improve health disparities; economic growth must be directed to social and medical resources that benefit communities and especially women.

While a benefit of the use of SEMs includes demonstrating some of the interrelationships involving droughts, food insecurity, women's status, and women's percentage of HIV, a common critique of cross-national research is the inability to empirically account for the exact processes by which many structural relationships take place. For example, risky sexual behaviors cannot be explicitly operationalized in our models, but it is likely a key factor explaining the links found between food insecurity and the percent of the adult population living with HIV who are women. To help address this weakness, we draw on evidence from relevant qualitative, survey, and case-study research to inform our understanding of the connections between food insecurity and women's vulnerability to HIV. Although our cross-national approach cannot fully capture individual behaviors, one of the benefits is in being able to generalize these findings across countries. While several individual-level studies in various locations document that hunger or food insecurity motivates participation in risky sex, early marriage, transactional sex, and commercial sex (e.g. Masa et al. 2019; Miller et al. 2011; Pellowski et al. 2018; Tsai and Weiser 2014), here we demonstrate that linkages between drought, food insecurity, women's status, and women's disproportionate vulnerability to HIV are applicable across a wide set of less-developed countries.

Our modeling strategy also uncovered important results regarding the influence of percent Muslim on the percent of HIV cases among women. We find that predominantly Muslim countries have lower rates of contraceptive use and more limited socio-heath conditions for women, which indirectly increase women's vulnerability to disease. These findings likely reflect the patriarchal nature of Muslim societies, which in relegating women's status also demotes women's health. However, percent Muslim also has a direct, negative influence on the percent of the adult population living with HIV who are women, perhaps due to the strict sexual and relationship norms that limit premarital sex and sex outside of marriage. Thus, the total impact of percent Muslim on the percent of HIV cases among women in less-developed countries is non-significant.

While the WHO estimates that over one-quarter of all deaths are directly attributable to environmental causes, there are many more deaths and illnesses that are likely to be indirectly related to environmental conditions, such as HIV. As women largely represent the environmental and household managers in developing countries, disasters and 
environmental decline are disproportionately and acutely devastating to women's health and well-being. Certainly, including women in environmental decision-making is of upmost importance. Unfortunately, gender inequalities pervade decision-making and policy, as the UN reports that women tend to be underrepresented in the decision-making on climate change at all levels (UN 2014). Our results also underscore that public health infrastructure is extremely important in reducing the devastating impacts of droughts in developing countries, and that during times of drought and hardship special attention should be made to ensuring the safety and participation of young women in schooling, medical care, and other activities that ensure their well-being. In addressing infectious diseases in poor countries, a holistic approach must be taken that not only emphasizes conventional approaches, like expanding access to medical care, but also prioritizing women's empowerment and environmental resilience and sustainability.

\section{References}

Agarwal, B. (1997). 'Bargaining' and gender relations: Within and beyond the household. Feminist Economics, 3(1), 1-51.

Arbuckle, J. L. (1996). Full information estimation in the presence of incomplete data. In G. A. Marcoulides \& R. E. Schumacker (Eds.), Advanced structural equation modeling. Mahwah, NJ: Lawrence Erlbaum Associates, Inc.

Austin, K. F., \& Noble, M. D. (2014). Measuring gender disparity in the HIV pandemic: A cross-national investigation of female empowerment, inequality, and disease in less-developed nations. Sociological Inquiry, 84(1), 102-130.

Austin, K. F., Choi, M. M., \& Berndt, V. (2017). Trading sex for security: Unemployment and the unequal HIV burden among young women in developing nations. International Sociology, 32(3), 343-368.

Belachew, T., Hadley, C., Lindstrom, D., Gebremariam, A., Lachat, C., \& Kolsteren, P. (2011). Food insecurity, school absenteeism and educational attainment of adolescents in Jimma Zone Southwest Ethiopia: A longitudinal study. Nutrition Journal, 10(1), 29-37.

Bollen, K. (1989). Structural equations with latent variables. Hoboken, NJ: Wiley-Interscience.

Carrington, D. (2020). Coronavirus: 'Nature is sending us a message', says UN environment chief. The Guardian. https://www.theguardian.com/world/2020/mar/25/coronavirus-nature-is-sending-us-a-messa ge-says-un-environment-chief. Accessed 15 March 2020.

CRED (Centre for Research on the Epidemiology of Disasters). (2016). Preliminary data: Human impact of natural disasters. CRED Crunch Issue, 45, 1-2.

Clark, R., \& Snawder, K. (2020). A cross-national analysis of lifespan inequality, 1950-2015: Examining the distribution of mortality within countries. Social Indicators Research, 148, 705-732.

Elmhirst, R. (2011). Introducing new feminist political ecologies. Geoforum, 42(2), 129-132.

FAO (Food and Agriculture Organization of the United Nations). (2011). Drought-related food insecurity: A focus on the Horn of Africa. http://www.fao.org/3/mb738e/mb738e.pdf. Accessed 10 March 2020.

FAO (Food and Agriculture Organization of the United Nations). (2020). Drought. http://www.fao.org/landwater/water/drought/en/. Accessed 10 March 2020.

Farmer, P. (1999). Infections and inequalities: The modern plagues. Berkeley, CA: University of California Press.

Friis, A., \& Michaelsen, K. F. (1998). Micronutrients and HIV infection: A review. European Journal of Clinical Nutrition, 52, 157-163.

Friis, H. (2005). Micronutrients and HIV infection: A review of current evidence. World Health Organization. https://www.who.int/nutrition/topics/Paper\%20Number\%202\%20-\%20Micronutrients.pdf. Accessed 15 March 2020.

Gebremichael, D. Y., Hadush, K. T., Kebede, E. M., \& Zegeye, R. T. (2018). Food insecurity, nutritional status, and factors associated with malnutrition among people living with HIV/AIDS attending antiretroviral therapy at public health hacilities in West Shewa Zone, Central Ethiopia. BioMed Research International, 2018(9), 1-9.

Gillespie, S., \& Kadiyala, S. (2005). HIV/AIDS and food and nutrition security: Interactions and response. American Journal of Agricultural Economics, 87(5), 1282-1288. 
Hadley, C., Stevenson, E., Tadesse, Y., \& Belachew, T. (2012). Rapidly rising food prices and the experience of food insecurity in urban Ethiopia: impacts on health and well-being. Social Science \& Medicine, 75(12), 2412-2419.

Heimer, C. A. (2007). Old inequalities, new disease: HIV/AIDS in sub-Saharan Africa. Annual Review of Sociology, 33, 551-577.

Hovorka, A. (2006). The No. 1 ladies' poultry farm: A feminist political ecology of urban agriculture in Botswana. Gender, Place and Culture, 13(3), 207-255.

Lartey, A. (2008). Maternal and child nutrition in sub-Saharan Africa: Challenges and interventions. Proceedings of the Nutrition Society, 67(1), 105-108.

Lewis, K. (2017). Understanding climate as a driver of food insecurity in Ethiopia. Climatic Change, $144,317-328$.

Marvel, K., Cook, B. I., Bonfils, C., Durack, P. J., Smerdon, J. E., \& Williams, A. P. (2019). Twentiethcentury hydroclimate changes consistent with human influence. Nature, 569, 59-65.

Masa, R., Graham, L., Khan, Z., Chowa, G., \& Patel, L. (2019). Food insecurity, sexual risk taking, and sexual victimization in Ghanaian adolescents and young South African adults. International Journal of Public Health, 64, 153-163.

Memon, M. H., Aamir, N., \& Ahmed, N. (2018). Climate change and drought: Impact of food insecurity on gender based vulnerability in district Tharparkar. The Pakistan Development Review, 57(3), 307-331.

Mies, M., \& Shiva, V. (1993). Ecofeminism. New York: Zed Books.

Miller, C. L., Bangsberg, D. R., Tuller, D. M., Senkungu, J., Kawuma, A., Frongillo, E. A., et al. (2011). Food insecurity and sexual risk in an HIV endemic community in Uganda. AIDS and Behavior, 15(7), 1512-1519.

Mojola, S. A. (2014). Love, money, and HIV: Becoming a modern African woman in the age of AIDS. Oakland, CA: University of California Press.

Momo, M. S. M., Cabus, S. J., De Witte, K., \& Groot, W. (2019). A systematic review of the literature on the causes of early school leaving in Africa and Asia. Review of Education, 7, 496-522.

Muula, A. S. (2008). HIV infection and AIDS among young women in South Africa. Croatian Medical Journal, 49(3), 423-435.

National Oceanic and Atmospheric Administration (NOAA). (2020). Definition of drought. https://www. ncdc.noaa.gov/monitoring-references/dyk/drought-definition. Accessed April 2020.

Opondo, M. Abdi, U., \& Nangiro, P. (2016). 'Assessing gender in resilience programming: Uganda'. BRACED: Resilience Intel. p. 11. Available from https://www.odi.org/sites/odi.org.uk/files/odiassets/publications-opinion-files/10215.pdf.

Pascoe, S. J. S., Langhaug, L. F., Mavhu, W., Hargreaves, J., Jaffar, S., \& Hayes, R. (2015). Poverty, food insufficiency and HIV infection and sexual behaviour among young rural Zimbabwean women. PLOS ONE, 10(1), e0115290.

Pellowski, J. A., Huedo-Medina, T. B., \& Kalichman, S. C. (2018). Food insecurity, substance use, and sexual transmission risk behavior among people living with HIV: A daily level analysis. Archives of Sexual Behavior, 47, 1899-1907.

Pew Research Center. (2009). World muslim population by region and country. Pew Research Center. https://www.pewforum.org/2009/10/07/mapping-the-global-muslim-population/\#map2. Accessed 10 December 2016.

Plumwood, V. (1993). Feminism and the mastery of nature. London: Routledge.

Rocheleau, D., Thomas-Slayter, B., \& Wangari, E. (Eds.). (1996). Feminist political ecology: Global issues and local experiences. London: Routledge.

Sam, A. S., Abbas, A., Padmaja, S. S., Kaechele, H., Kumar, R., \& Müller, K. (2019). Linking food security with household's adaptive capacity and drought risk: Implications for sustainable rural development. Social Indicators Research, 142, 363-385.

Smith, M. K. (2002). Gender, poverty, and intergenerational vulnerability to HIV/AIDS. Gender and Development, 10(3), 63-70.

Stillwaggon, E. (2002). HIV/AIDS in Africa: Fertile terrain. The Journal of Development Studies, 38(2), $1-22$.

Stoebenau, K., Heise, L., Wamoyi, J., \& Bobrova, N. (2016). Revisiting the understanding of "transactional sex" in sub-Saharan Africa: A review and synthesis of the literature. Social Science \& Medicine, 168, 186-197.

Tierney, K. (2019). Disasters: A sociological approach. Cambridge: Polity Press.

Tsai, A. C., \& Weiser, S. D. (2014). Population-based study of food insecurity and HIV transmission risk behaviors and symptoms of sexually transmitted infections among linked couples in Nepal. AIDS and Behavior, 18(11), 217-219. 
Tsai, A. C., Hung, K. J., \& Weiser, S. D. (2012). Is food insecurity associated with HIV risk? Crosssectional evidence from sexually active women in Brazil. PLoS Medicine, 9(4), e1001203.

Union of Concerned Scientists (UCSUSA). (2014). Drought and climate change http://www.ucsusa.org. Accessed 15 November 2019.

UN (United Nations). (2019). World population prospects 2019: Highlights. United Nations. https://popul ation.un.org/wpp/Publications/Files/WPP2019_10KeyFindings.pdf. Accessed 15 March 2020.

UNAIDS. (2017). When women lead, change happens. UNAIDS. https://www.unaids.org/sites/default/files/ media_asset/when-women-lead-change-happens_en.pdf. Accessed 15 March 2020.

UNEP (United Nations Environment Programme). (2016). Frontiers 2016: Emergent issues of environmental concern. United Nations Environment Programme. https://www.unenvironment.org/resources/front iers-2016-emerging-issues-environmental-concern. Accessed 15 March 2020.

Weiser, S. D., Leiter, K., Bangsberg, D. R., Butler, L. M., Percy-de Korte, F., Hlanze, Z., et al. (2007). Food insufficiency is associated with high-risk sexual behavior among women in Botswana and Swaziland. PLoS Medicine, 4(10), 1589-1598.

Wisner, B., Blaikie, P., Cannon, T., \& Davis, I. (2004). At risk: Natural hazards, people's vulnerability, and disasters (2nd ed.). Routledge: New York.

World Health Organization (WHO). (2018). HIV/AIDS. World Health Organization. https://www.who.int/ news-room/fact-sheets/detail/hiv-aids. Accessed 15 March 2020.

World Bank. (2012). Severe droughts drive food prices higher, threatening the poor. https://www.worldbank. $\mathrm{org} / \mathrm{en} /$ news/press-release/2012/08/30/severe-droughts-drive-food-prices-higher-threatening-poor. Accessed 5 November 2020.

World Bank. (2019). World development indicators. Retrieved from https://databank.worldbank.org/data/ source/world-development-indicators\#. Accessed 15 March 2020.

Publisher's Note Springer Nature remains neutral with regard to jurisdictional claims in published maps and institutional affiliations. 